\title{
EFEITO DE ÓLEOS ESSENCIAIS CÍTRICOS SOBRE Agrotis ipsilon (HUFNAGEL) (LEPIDOPTERA:NOCTUIDAE)
}

\author{
Ingrid Schimidt Kaiser ${ }^{1}$ \\ Sabrina Buqueroni Alves ${ }^{2}$ \\ Breno Benvindo dos Anjos ${ }^{3}$ \\ Débora Ferreira Melo Fragoso ${ }^{4}$ \\ Julielson Oliveira Ataide ${ }^{5}$ \\ Dirceu Pratissoli ${ }^{6}$
}

Resumo: A utilização de plantas inseticidas é cada vez mais frequente no controle de pragas. As plantas podem produzir diferentes compostos com atividade inseticida. Os óleos essenciais destacam-se dentre estes compostos, possuindo diferentes modos de ação inseticida, podendo ser uma ferramenta útil no manejo integrado de pragas. O objetivo deste trabalho é avaliar o efeito de óleos essenciais citricos e seu composto majoritário D-limonemo visando sua adoção como métodos alternativos de controle de $\underline{\text { Agrotis }}$ ipsilon (Hufnagel) (Lepidoptera: Noctuidae). Para a realização do experimento foram utilizadas 50 lagartas de $1^{\circ}$ instar por tratamento. Foram aplicados os óleos essenciais com auxilio do aerógrafo, sendo utilizado na concentração de $10 \% v v^{-1}$ para os óleos cítricos e o D-limoneno e para testemunha foi pulverizado água destilada. A avaliação foi realizada após 24, 48 e 72 horas verificando o número de lagartas mortas. Não foi observado efeito tóxico dos óleos essenciais cítricos e do $D$-limoneno sobre as lagartas de $\underline{A}$. $\underline{\underline{i p s i l o n}}$. Deste modo, os óleos essenciais testados não são eficazes no controle da praga.

Palavras-chave Lagarta rosca; Planta inseticida; Óleo essencial; Manejo integrado de pragas.

\footnotetext{
${ }^{1}$ Doutoranda em Entomologia/Escola Superior Luiz de Queiroz/Universidade de São Paulo, Piracicaba/SP, Brasil. E-mail: ingrid_schimidt@hotmail.com.

${ }^{2}$ Graduanda em Ciências Biológicas Licenciatura /Universidade Federal do Espírito Santo, Alegre/ES, Brasil. Email: sabrinabuqueroni21@gmail.com.

3 Mestrando em Produção Vegetal, Universidade Federal do Espírito Santo, Alegre/ES, Brasil. E-mail: bbdanjos@gmail.com.

${ }^{4}$ Pós-Doutoranda, Universidade Federal do Espírito Santo, Alegre/ES, Brasil, E-mail: debmelo@gmail.com.

5 Mestrando em Produção Vegetal, Universidade Federal do Espírito Santo, Alegre/ES, Brasil. E-mail: julielsonoliveira@hotmail.com.

${ }^{6}$ Professor Titular, Universidade Federal do Espírito Santo, Alegre/ES, Brasil. E-mail: pratissoli@cca.ufes.br.
} 